10,13

\title{
Изменение строения поверхности гетерогенного нанокристаллического тела (песчаника) при трении
}

\author{
() В.И. Веттегрень ${ }^{1}$, А.В. Пономарев ${ }^{2}$, Г.А. Соболев ${ }^{2}$, И.П. Щербаков ${ }^{1}$, \\ Р.И. Мамалимов ${ }^{1}$, В.Б. Кулик ${ }^{1}$, А.В. Патонин ${ }^{3}$ \\ ${ }^{1}$ Физико-технический институт им. А.Ф. Иоффе РАН, \\ Санкт-Петербург, Россия \\ ${ }^{2}$ Институт фоизики Земли им. О.Ю. Шмидта РАН, \\ Москва, Россия \\ ${ }^{3}$ Геофизическая обсерватория „Борок“ - филиал Института фризики Земли им. О.Ю. Шмидта РАН, \\ Борок, Россия \\ E-mail: Victor.Vettegren@mail.ioffe.ru
}

(Поступила в Редакцию 3 августа 2016 г.)

\begin{abstract}
Методами фотолюминесценции и рамановской спектроскопии исследовано строение поверхностного слоя толщиной $\sim 30 \mathrm{~nm}$ гетерогенного нанокристаллического твердого тела - песчаника до и после трения. До трения этот слой содержал нанокристаллы кварца, анатаза, полевого шпата и монтмориллонита. Трение вызвало резкое уменьшение концентрации нанокристаллов кварца и полевого шпата.
\end{abstract}

Работа выполнена при финансовой поддержке Российского фонда фундаментальных исследований (грант № 16-05-00137).

DOI: 10.21883/FTT.2017.03.44172.319

\section{1. Введение}

Согласно современным представлениям в основе возникновения землетрясений лежит неустойчивость скольжения земных плит [1-4]. Она может быть порождена резкими изменениями величины коэффициента трения на контактах пород. Существуют несколько гипотез, объясняющих это явление. В одной из них предполагается, что при трении породы измельчаются до наноразмеров $[4,5]$. Другая гипотеза исходит из предположения, что между блоками породы образуется насыщенный флюидом минеральный агрегат [6]. В основу третьей положено предположение, что при трении контактирующие породы нагреваются до расплавления [7-8].

В результате трения поверхности контактирующих пород часто сглаживаются и образуются так называемые „зеркала скольжения“. Исследование строения поверхности таких зеркал может дать сведения о причинах неустойчивости скольжения. Первое прямое исследование строения зеркала скольжения, образовавшегося на поверхности нанокристаллического гетерогенного твердого тела - песчаника, было проведено в работе [9]. С использованием методов инфракрасной и рамановской спектроскопии было обнаружено, что зеркало скольжения состоит из деформированных нанокристаллов монтмориллонита и анатаза с линейными размерами $\sim 15$ и $\sim 3 \mathrm{~nm}$ соответственно. Затем методами инфракрасной, рамановской и фотолюминесцентной спектроскопии было исследовано строение зеркал скольжения на поверхности порфирита и доломита $[10,11]$. Установлено, что поверхностные слои этих пород также содержат деформированные нанокристаллы.
Настоящая работа поставлена с целью выяснить можно ли при трении песчаника в условиях лаборатории получить поверхность, строение которой аналогично строению природного зеркала скольжения.

\section{2. Методика эксперимента}

Образцы готовили из блоков штуфов песчаника полуострова Средний на северном побережье Кольского полуострова. Блоки разрезали на пластины с линейными размерами $25 \times 40 \times 10 \mathrm{~mm}$. Затем их надрезали на глубину $0.5 \mathrm{~mm}$ и раскалывали по надрезу (рис. 1). Полученные образцы выдерживали в воде в течение 3 часов. Таким образом формировались поверхности песчаника, насыщенные водой с естественной неровностью, без дополнительной обработки абразивными инструментами. Предполагалось, что неровная поверхность граней насыщенного водой образца может служить моделью земной породы перед началом процесса трения.

Конструкция для трения [12] основана на „sandwich model $^{\text {“, }, ~ п р е д л о ж е н н о и ̆ ~ в ~}[1,2]$ (рис. 2).

В ней три образца (3) зажимались стальными пластинами (2) толщиной $20 \mathrm{~mm}$. К ним прикладывалось „боковое“ давление $F_{2}$. Для предотвращения смещения боковых пластин образца их нижняя часть опирается на стальные упоры (4). Осевая нагрузка $F_{1}$, создаваемая прессом, прикладывается к центральной пластине модели через пружину (1). Модель помещалась в пресс INOVA. C помощью программы управления прессом задавался режим нагружения, при котором смещение поршня пресса происходит со средней скоростью $0.488 \mu \mathrm{m} / \mathrm{s}$. Одновременно регистрировалось поло- 


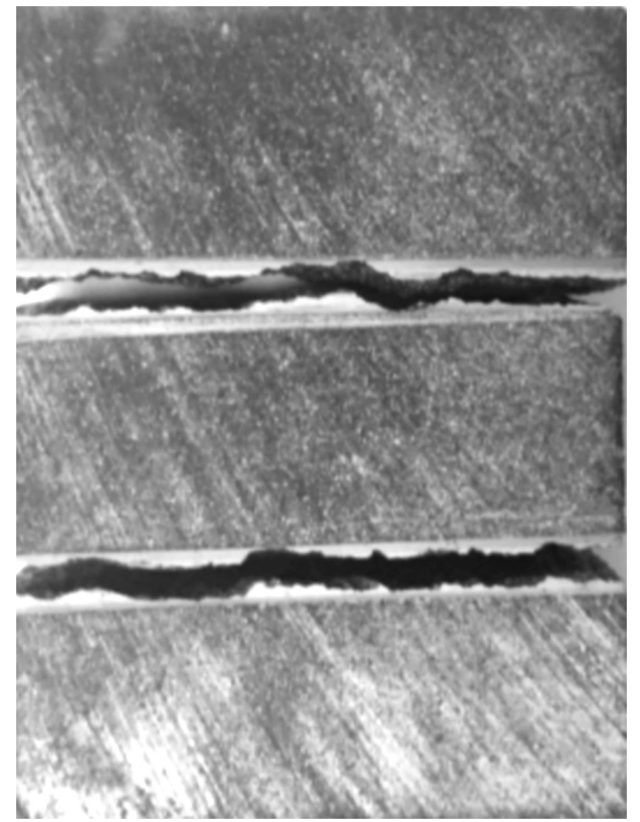

Рис. 1. Фотография, иллюстрирующая способ приготовления образца.

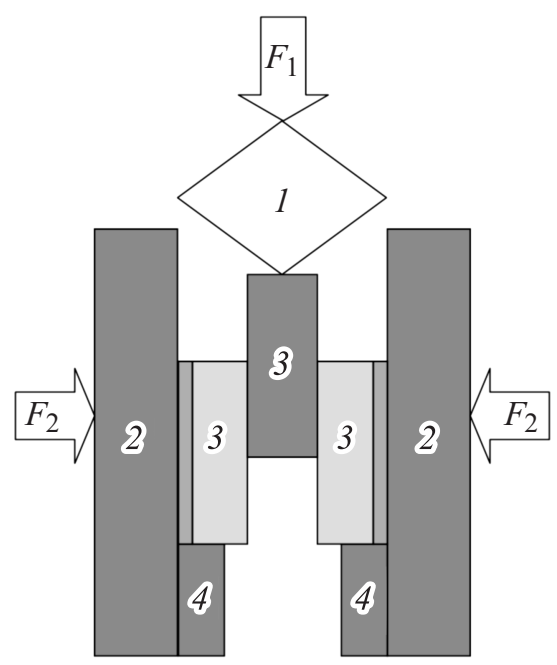

Pис. 2. Схема нагружения образцов песчаника. 1 - пружина, 2 - стальные пластины, 3 - образцы, 4 - упоры.

жение поршня пресса и создаваемое усилие. Комплект из трех пластин зажимали в оправках через резиновые прокладки - амортизаторы, чтобы уменьшить влияние неровностей внешних граней на результаты измерений.

Основным методом исследования изменений строения поверхностей пластин до и после трения являлась фотолюминесцентная (PL) спектроскопия. PL возбуждали ультрафиолетовым светодиодом HPL-H44LV1CO, который имеет интенсивную линию $-370 \mathrm{~nm}$ и несколько менее интенсивных линий. Чтобы погасить эти слабые линии, излучение светодиода пропускалось через фильтр UFS-8.
Излучение светодиода фокусировалось на поверхность исследуемого образца в пятно диаметром $2 \mathrm{~mm}$. Угол между направлением луча и нормалью к поверхности образца составлял $10^{\circ}$. Регистрация спектра PL ocyществлялась оптоволоконным спектрометром AvaSpecULSi2048L-USB2 OEM.

Для оценки размеров нанокристаллов анатаза и кварца была привлечена рамановская спектроскопия. Спектры возбуждали аргоновым лазером $\mathrm{Ar}^{2+} 16508$, линия $488 \mathrm{~nm}$, луч которого фокусировался на поверхность образца в пятно диаметром $\sim 30 \mu \mathrm{m}$. Спектры записывали на спектрометре Ramalog 5. Угол рассеяния - $180^{\circ}$.

Оба метода позволяют получить информацию о строении поверхностного слоя, эффективная толщина $h$ которого задана глубиной, на которой интенсивность поля электромагнитного излучения затухает в $\sim 8$ раз. Значение $h$ вычислялось по формуле [13]

$$
h \approx 1 / 4 \pi v k
$$

где $k$ - показатель поглощения, а $v-$ частота линии источника излучения.

Для определения $k$ измеряли коэффициент отражения $R$ породы на частоте источника. Известно, что значение $R$ при нормальном падении света связано с показателями преломления $-n$ и поглощения $k$ следующим уравнением [13]

$$
R=\frac{(n-1)^{2}+k^{2}}{(n+1)^{2}+k^{2}}
$$

Показатель преломления $n$ большинства горных пород в видимой области спектра равен 1.5 [14]. Используя это значение и измеренную величину коэффициента отражения - $R$, нашли значение $k$ и по формуле (1) рассчитали $h$. Оказалось, что использование метода PL спектроскопии позволяет получить сведения о строении поверхностного слоя, толщина которого $\sim 30 \mathrm{~nm}$, а рамановской спектроскопии - 70 nm.

\section{3. Строение поверхностного слоя образцов песчаника до трения}

На рис. 3 показана фотография поверхности образца до трения. На ней видно множество кластеров белого цвета на темном фоне. Размеры кластеров варьируют от нескольких десятых до $\sim 2 \mathrm{~mm}$.

Чтобы выяснить строение кластеров, анализировали PL спектры поверхностного слоя исследованного образца. Оказалось, что, когда луч лазера попадает внутрь кластеров, в спектре наблюдаются три полосы (рис. 4), энергия максимумов которых 2.6, 2.81 и $2.98 \mathrm{eV}$.

Две из них, 2.6 и $2.81 \mathrm{eV}$, приписаны самозахваченным экситонам [15], а третья - $2.98 \mathrm{eV}-$ кислородной вакансии [16] в кристаллах кварца.

Когда луч лазера попадает в темные области, интенсивность PL уменьшается приблизительно на два порядка, и в спектре появляются новые, наложенные друг 


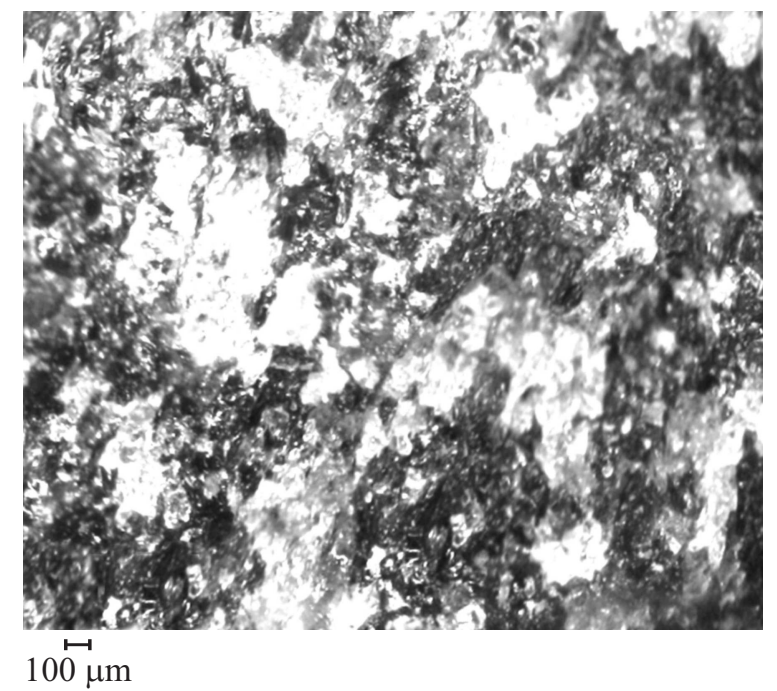

Рис. 3. Фотография поверхности образца до трения.

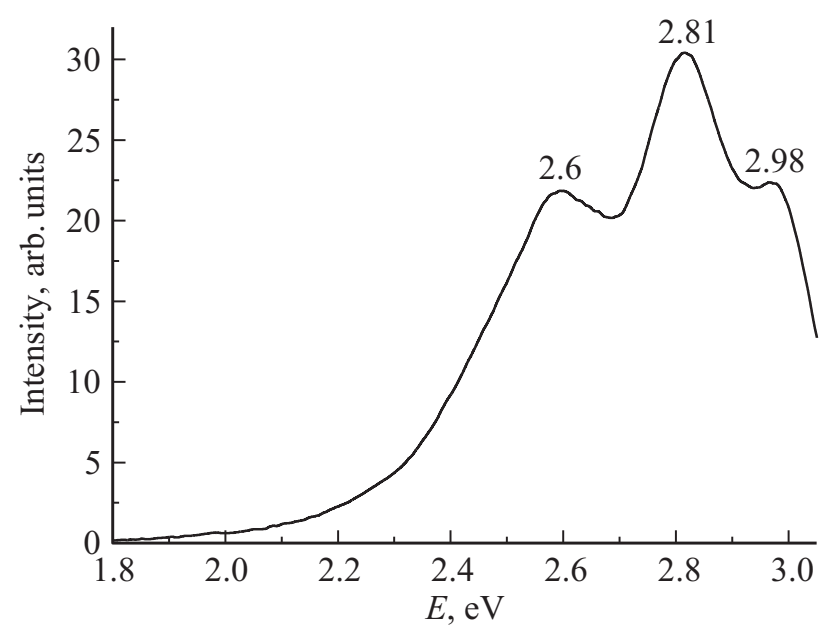

Рис. 4. Спектр PL кластеров.

на друга максимумы (рис. 5). Максимумы 1.8 и $1.98 \mathrm{eV}$ соответствуют ионам $\mathrm{Fe}^{3+}$ и $\mathrm{Eu}^{3+}$ в монтмориллоните $[17,18], 2.1,2.2$ и $2.65 \mathrm{eV}$ кислородным вакансиям и ионам $\mathrm{Mn}^{2+}$ и $\mathrm{Eu}^{2+}$ в полевых шпатах [15], а 2.4 и $2.9 \mathrm{eV}$ - кислородным вакансиям и самозахваченным экситонам в анатазе $[19,20]$.

Эти результаты показывают, что поверхностный слой образца толщиной $30 \mathrm{~nm}$ содержит дефектные (т.е. содержащие собственные дефекты и примесные ионы) кристаллы монтмориллонита, кварца, полевых шпатов и анатаза.

В работах [9,21-23] было установлено, что все указанные кристаллы в песчанике имеют наноразмеры. Оценим размеры кристаллов в исследуемых образцах песчаника. С этой целью анализировали форму полос в рамановских спектрах (рис. 6).

Наблюдаемые в этих спектрах полосы приписаны колебаниям кристаллических решеток анатаза $[24]-143.3,398$ и $635 \mathrm{~cm}^{-1}$, монтмориллони- та $[25]-194$ и $715 \mathrm{~cm}^{-1}$, кварца [26-28] - 206, 360 и $463.2 \mathrm{~cm}^{-1}$ и полевых шпатов [29-31] - 240, 265, 293, $330,511,575,675$ и $746 \mathrm{~cm}^{-1}$.

Таким образом, анализ рамановских спектров согласуется с результатами исследования содержания минералов в поверхностном слое песчаника методом PL спектроскопии.

Известно, что полосы в рамановских спектрах макрокристаллов имеют симметричную дисперсионную форму, т.е. зависимость интенсивности $I$ от частоты $v$ описывается выражением [32]

$$
I(v)=\frac{I_{0}(\Gamma / 2)^{2}}{\left(v_{0}-v\right)^{2}+(\Gamma / 2)^{2}},
$$

где $I_{0}$ - интенсивность в максимуме полосы на частоте $v_{0}$, а $\Gamma$ - ее ширина (на половине $I_{0}$ ).

Такая форма обусловлена нелинейностью сил межатомного взаимодействия, которая вызывает обмен энергией между различными модами колебаний кристаллической решетки и биения их амплитуды. По этой

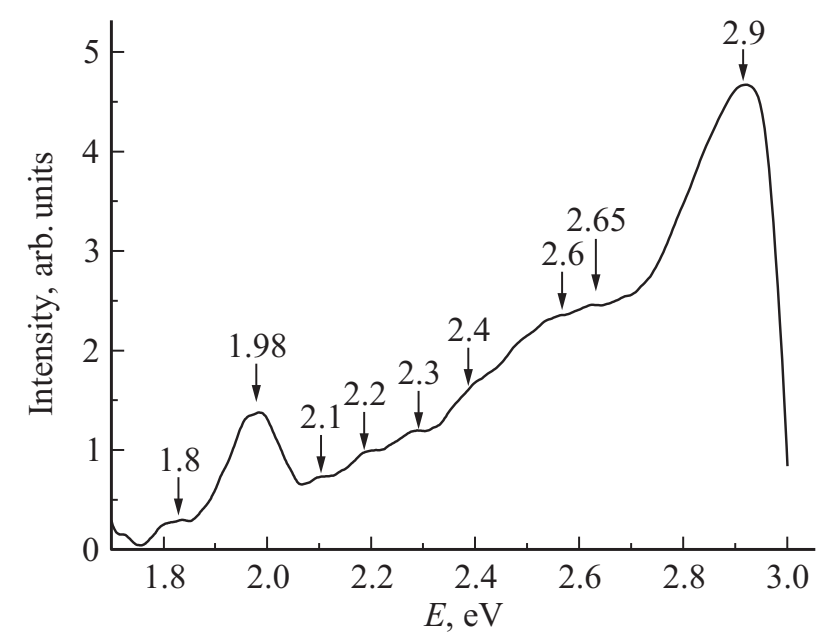

Рис. 5. Спектр PL темных областей.

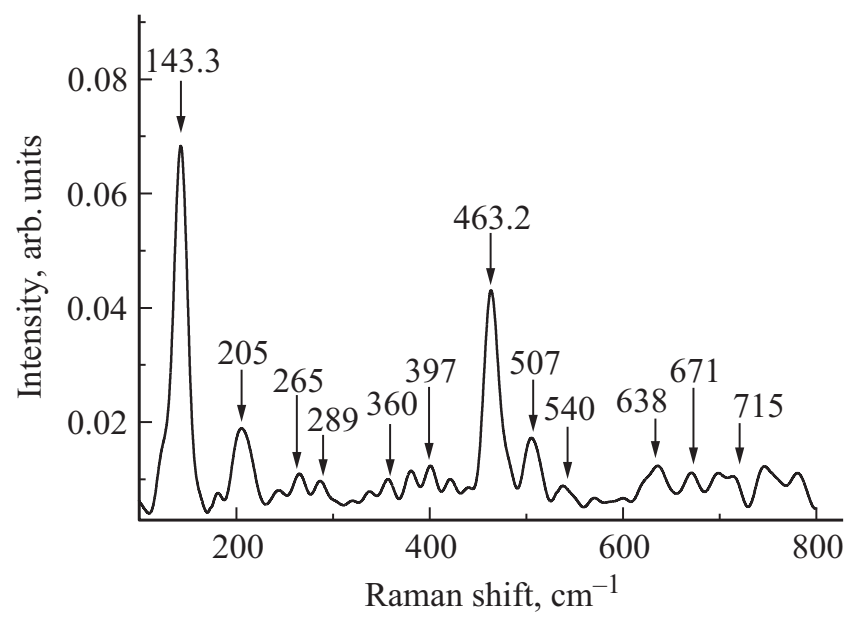

Рис. 6. Рамановский спектр песчаника. 


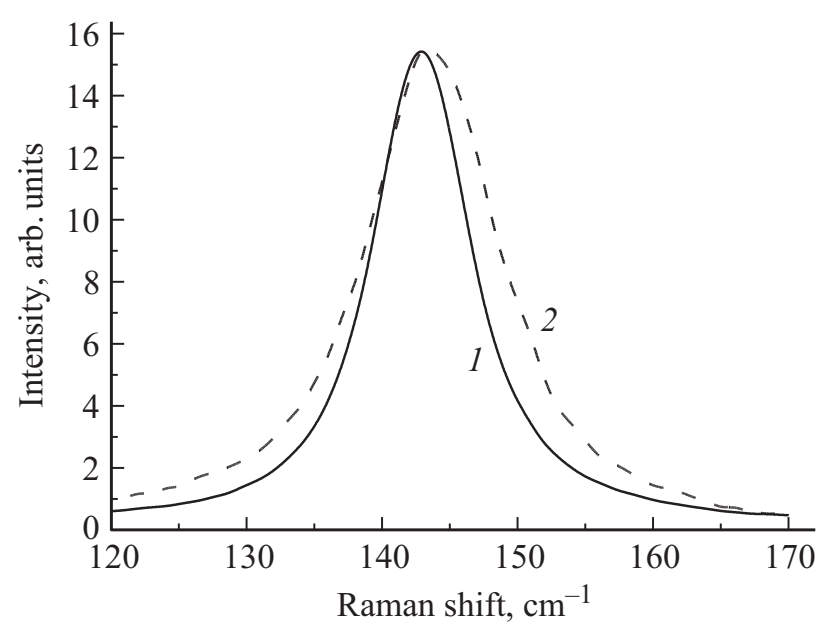

Рис. 7. Полоса $143.3 \mathrm{~cm}^{-1}$, приписанная колебаниям кристаллической решетки анатаза в рамановских спектрах макрокристалла (1) и поверхностного слоя образца песчаника (2).

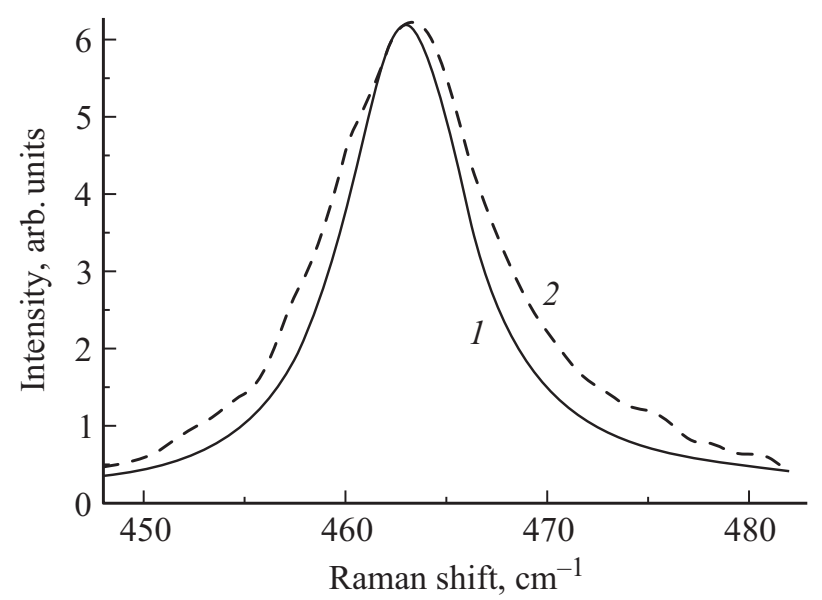

Рис. 8. Полоса $463.2 \mathrm{~cm}^{-1}$, приписанная колебаниям кристаллической решетки кварца в рамановских спектрах макрокристалла (1) и поверхностного слоя образца песчаника (2).

причине „время жизни“ $\tau-$ кванта нормального колебания - фонона составляет $\approx 10^{3}$ периодов колебаний. За это время фононы распространяются на расстояние $\Lambda=v_{p} \tau \approx 10-100 \mathrm{~nm}\left(v_{p}-\right.$ скорость пробега фононов). В результате взаимодействия света с колебанием, амплитуда которого изменяется со временем, в спектре появляется полоса, имеющая дисперсионную форму и ширину $\Gamma=1 / S \tau$, где $S-$ скорость света [30]. Именно такую - дисперсионную форму имели полосы для макрокристаллов кварца и анатаза (см. рис. 7 и 8).

Однако в рамановских спектрах исследованных образцов песчаника форма наиболее интенсивных полос кварца и анатаза (рис. 7 и 8) не является дисперсионной: они несимметрично уширены со стороны высоких частот. (Для удобства сравнения спектров интенсивность в максимуме полос на этих рисунках подогнана к одной и той же величине).
Асимметрия вызвана тем, что кристаллы кварца и анатаза имеют нанометровые размеры. По этой причине за время своей жизни колебания успевают добежать до границы кристалла и рассеяться на ней. Это приводит к наблюдаемой асимметрии полос [33,34] и может быть использовано для оценки размеров нанокристаллов [9-11,21-23].

Форма полосы в рамановских спектрах нанокристаллов имеет вид [33-35]

$$
I(v) \cong \int \frac{\left|C(0,|\mathbf{q}|)^{2}\right| d^{3} q}{(v-v(q))^{2}+\left(\Gamma_{0} / 2\right)^{2}},
$$

где $v(q)$ - дисперсия, $|\mathbf{q}|-$ абсолютная величина волнового вектора фонона (кванта колебаний кристаллической решетки), $C\left(q_{0}, q\right)$ - коэффициент Фурье волновой функции $\Psi\left(q_{0}, r\right)$,

$$
C\left(q_{0}, q\right)=\frac{1}{(2 \pi)^{3}} \int \Psi\left(q_{0}, r\right) \exp \left(-i q_{0} r\right) d^{3} r
$$

$q_{0}$ - волновой вектор фонона исследуемого колебания для кристалла макроскопических размеров, $r$ - вектор, величина которого равна расстоянию от точки, в которой амплитуда колебаний имеет наибольшее значение.

В предположении, что нанокристаллы имеют вид сферы [33-35]:

$$
|C(0, q)|^{2}=\exp \left(-\frac{-q^{2} d^{2}}{16 \pi^{2}}\right),
$$

где $d$ - диаметр нанокристалла.

Для колебания $143.3 \mathrm{~cm}^{-1}$ в рамановском спектре анатаза зависимость частоты от волнового вектора фонона имеет вид [33]

$$
v(q)=v_{0}+20(1-\cos a q),
$$

где $a=0.38 \mathrm{~nm}[36]$ - среднее межатомное расстояние.

Для колебаний $463.3 \mathrm{~cm}^{-1}$ кристаллической решетки кварца зависимость частоты от волнового вектора описывается выражением [37]

$$
v(q)=v_{0}+9.5 a q
$$

где $a \approx 0.49 \mathrm{~nm} \mathrm{[38].}$

Используя выражения (2)-(5), мы подбирали значения частоты колебаний нанокристаллов $v_{0}$ и их среднего диаметра $d$, которые наилучшим образом описывают форму полос. Оказалось, что для нанокристаллов анатаза $d \approx 8 \mathrm{~nm}$ и $v_{0}=141.9 \mathrm{~cm}^{-1}$, а для нанокристаллов кварца $d \approx 13 \mathrm{~nm}$ и $\nu_{0}=464.9 \mathrm{~cm}^{-1}$.

K сожалению, нам не удалось найти полос, соответствующих колебаниям кристаллических решеток монтмориллонита и полевых шпатов, в достаточной мере изолированных от наложения крыльев других полос. Это не позволило выяснить, имеют ли кристаллы полевых шпатов нано- или макроразмеры. Однако известно, что монтмориллонит всегда существует только в виде нанокристаллов [39]. Так, в [9] было найдено, что размеры нанокристаллов монтмориллонита на поверхности натурального зеркала скольжения составляют $\sim 15 \mathrm{~nm}$. 


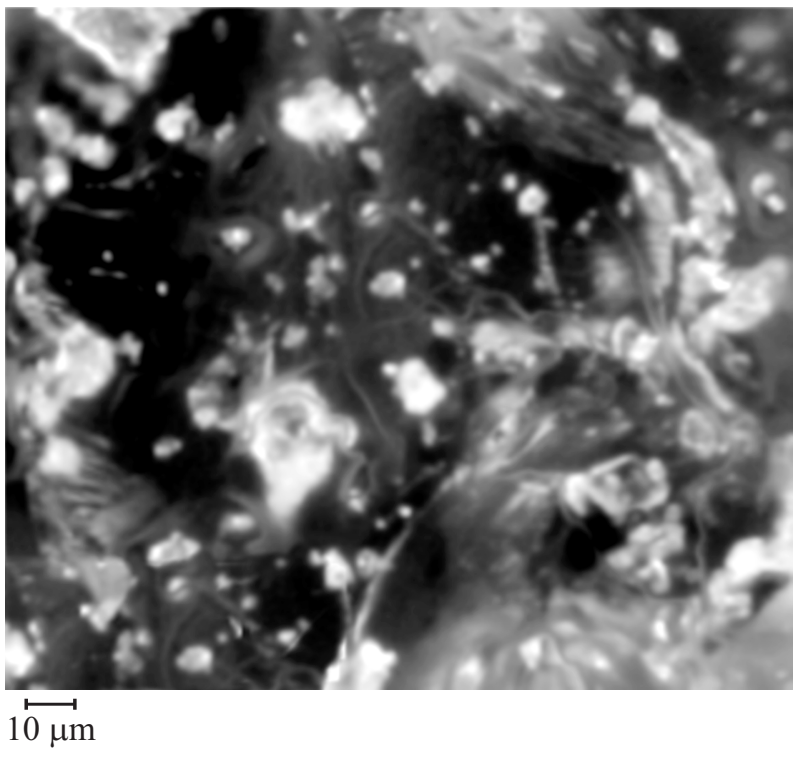

Рис. 9. Фотография поверхности образца после трения.

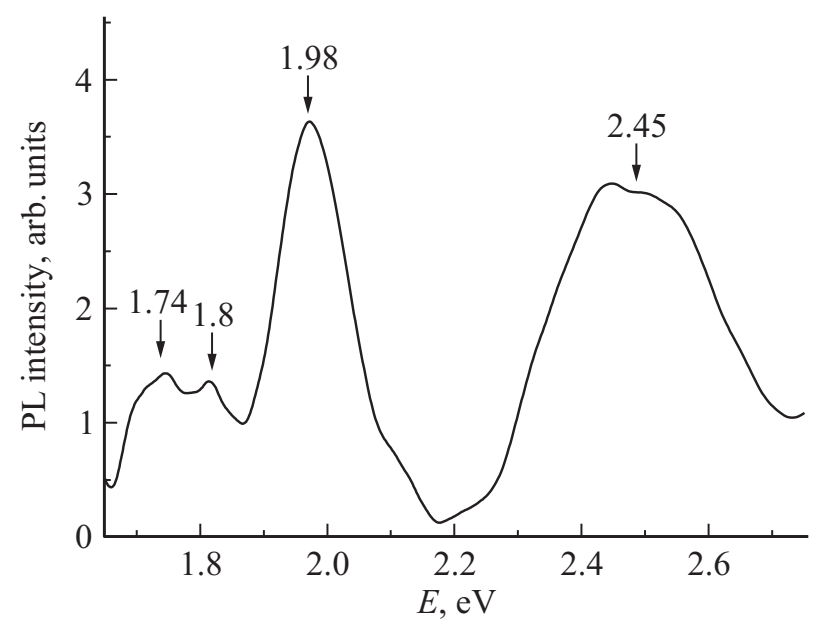

Pис. 10. Спектр PL темных областей на поверхности образца песчаника после трения.

\section{4. Строение образца песчаника после трения}

Рассмотрение поверхности образца после трения в оптический микроскоп показывает (рис. 9), что размеры структурных образований резко (на $\sim 2$ порядка) уменьшаются. Одновременно площадь темных областей становится по крайней мере в три раза больше площади, занятой белыми кластерами. Это показывает, что концентрация нанокристаллов кварца уменышается в три раза.

На рис. 10 показан PL спектр темных областей на поверхности песчаника после трения.

Полосы 1.74, 1.8 и $1.98 \mathrm{eV}$ в этом спектре приписаны ионам $\mathrm{Fe}^{3+}$ и $\mathrm{Eu}^{3+}$ в монтмориллоните [16,17], а $2.45 \mathrm{eV}$ - кислородным вакансиям в анатазе [18].
Напомним, что природное зеркало скольжения содержит только кристаллы монтмориллонита и анатаза. Вышеприведенные результаты показывают, что при трении в условиях лаборатории строение поверхностного слоя толщиной $\sim 30 \mathrm{~nm}$ приближается к строению природного зеркала. А именно, при трении нанокристаллы кварца и полевого шпата разрушаются. Как и в природном зеркале скольжения, остаются только нанокристаллы анатаза и монтмориллонита.

\section{5. Вывод}

При трении содержание нанокристаллов в поверхностном слое песчаника толщиной $30 \mathrm{~nm}$ изменяется. А именно, нанокристаллы кварца и полевого шпата разрушаются. На поверхности образуется новый слой, в котором содержатся только нанокристаллы анатаза и монтмориллонита.

\section{Список литературы}

[1] C.H. Scholz. The mechanics of earthquakes and faulting. Cambridge University Press (2002). 471 p.

[2] J.H. Dietrich. J. Geophys. Res. 77, 3690 (1972).

[3] J.H. Dietrich. Pure \& Appl. Geophys. 116, 790 (1978).

[4] G. Di Toro, R. Han, T. Hirose, N. De Paola, S. Nielsen, K. Mizoguchi, F. Ferri, M. Cocco, T. Shimamoto. Nature 471. 494 (2011).

[5] G.-Y. Wang, M. Manga. Earthquakes and water. BerlinHeidelberg, Springer (2010). 225 p.

[6] Y. Fialko, Y. Khazan. J. Geoph. Res. 110, B12407 (2005).

[7] S. Nielsen, G. Di Toro, T. Hirose, T. Shimamoto. J. Geoph. Res. 113, B 01308 (2008).

[8] В.В. Ружич. Геология и геофизика, 11, 39 (1989).

[9] Г.А. Соболев, С.М. Киреенкова, Ю.А. Морозов, А.И. Смульская, В.И. Веттегрень, В.Б. Кулик, Р.И. Мамалимов. Физика Земли 9-10, 17 (2012).

[10] Г.А. Соболев, В.И. Веттегрень, В.В. Ружич, Л.А. Иванова, Р.И. Мамалимов, И.П. Щербаков. Вулканология и сейсмология 3, 3 (2015).

[11] Г.А. Соболев, В.И. Веттегрень, В.В. Ружич, С.М. Киреенкова, А.И. Смульская, Р.И. Мамалимов, В.Б. Кулик. Геофизические исследования 17, 4, 5 (2015).

[12] А.В. Патонин, А.В. Пономарев, В.Б. Смирнов. Сейсмические приборы 49, 1, 19 (2013).

[13] M. Born, E. Wolf. Principles of optics. Pergamon press, Oxford (1964). $856 \mathrm{p}$.

[14] W. Schumann. Gemstones of the world. Sterling, N. Y. (1997). $272 \mathrm{p}$.

[15] J. Götze. Microsc. Microanal. 18, 1270 (2012).

[16] А.Ф. Зацепин. ФТТ 52, 1104 (2010).

[17] N. Mizukami, M. Tsujimura, K. Kuroda1, M. Ogawa. Clays Glay Miner. 50, 799 (2002).

[18] C.R. Cousins, A.D. Griffiths, I.A. Crawford, B.J. Prosser, M.C. Storrie-Lombardi. Astrobiology 10, 933 (2010).

[19] Ch. Jin, B. Liu, Z. Lei, J.Sun. Nanoscale Res. Lett. 10, 95 (2015).

[20] B. Santara, P.K. Giri, K. Imakita, M. Fujii. Nanoscale. 5, 5476 (2013). 
[21] Г.А. Соболев, В.И. Веттегрень, С.М. Киреенкова, В.Б. Кулик, Ю.А. Морозов, А.И. Смульская. Физика Земли 6, 7 (2007).

[22] Г.А. Соболев, В.И. Веттегрень, С.М. Киреенкова, В.Б. Кулик, Ю.А. Морозов, А.И. Смульская. Геофизический журн. 29, 3, 10 (2007).

[23] В.Б. Кулик, Г.А. Соболев, В.И. Веттегрень, С.М. Киреенкова. Физика Земли 10, 19 (2011).

[24] H. Zhang, M. Zhou, Q. Fu, B. Lei, W. Lin, H. Guo, M. Wu, Y. Lei. Nanotechnology 25, 275603 (2014).

[25] C. Jin, Ben Liu, Z. Lei, J. Sun. Nanoscale. Res. Let. 10, 95 (2015).

[26] M. Wu, W. Zhang, Z. Du, Y. Huang. Modern Phys. Lett. 13, 5, 167 (1999).

[27] R.L. Frost, L. Rintoul. Appl. Clay Sci. 11, 2-4, 171 (1996).

[28] P. Umari, A. Pasquarello, A. Dal Corso. Phys. Rev. B 63, 094305 (2001).

[29] K.J. Kingma, R.J. Hemley. Am. Mineral. 79, 269 (1994).

[30] Y. Liang, C.R. Miranda, S. Scandolo. J. Chem. Phys. 125, 194524 (2006).

[31] J.J. Freeman, A. Wang, K.E. Kuebler, B.L. Jolliff, L.A. Haskin. Canad. Mineral 46, 1477 (2008).

[32] O. Madelung. Festkopertheorie. Springer-Verlag, Berlin (1972). $418 \mathrm{p}$.

[33] H. Richter, Z.P. Wang, L. Ley. Solid State Commun. 39, 625 (1981).

[34] K.K. Tiong, P.M. Amirtharagj, F.H. Pollak, D.E. Aspness. Appl. Phys. Lett. 44, 122 (1984).

[35] M. Ivanda, S. Musi/'c, M. Goti/.e, A. Turkovi/'c, A.M. Tonejc, O. Gamulin. J. Mol. Struct. 480-481. 641(1999).

[36] W.F. Zhang, Y.L. He, M.S. Zhang, Z. Yin. Q.J. Phys. D. 33. 912 (2000).

[37] D. Strauch, B. Dorner. J. Phys.: Condens. Matter. 5, 6149 (1993).

[38] L. Levien, C.T. Prewitt, D. Weidner. Am. Mineral. 65, 920 (1980).

[39] G. Brown. Crystal Structures of Clay Minerals and their X-Ray Identification. Mineral. Soc., London (1982). 518 p. 